\title{
Marked hyperandrogenicity in a 60-year-old woman
}

\author{
Khaled Aljenaee1, Sulaiman Ali2, Seong Keat Cheah', Owen MacEneaney3, Niall Mulligan³, \\ Neil Hickey ${ }^{4}$ Tommy Kyaw Tun', Seamus Sreenan' ${ }^{1}$ and John H McDermott ${ }^{1}$
}

1Department of Endocrinology, Royal College of Surgeons in Ireland, Connolly Hospital Blanchardstown, Dublin, Ireland, 2Departments of Endocrinology and ${ }^{3 H i s t o p a t h o l o g y, ~ M a t e r ~ M i s e r i c o r d i a e ~ U n i v e r s i t y ~}$

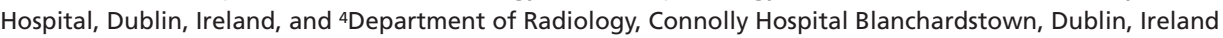

\section{Correspondence} should be addressed to K Aljenaee Email

k.jenaee@gmail.com

\section{Summary}

Markedly elevated androgen levels can lead to clinical virilization in females. Clinical features of virilization in a female patient, in association with biochemical hyperandrogenism, should prompt a search for an androgen-producing tumor, especially of ovarian or adrenal origin. We herein report the case of a 60-year-old woman of Pakistani origin who presented with the incidental finding of male pattern baldness and hirsutism. Her serum testosterone level was markedly elevated at $21 \mathrm{nmol} / \mathrm{L}$ (normal range: $0.4-1.7 \mathrm{nmol} / \mathrm{L}$ ), while her DHEAS level was normal, indicating a likely ovarian source of her elevated testosterone. Subsequently, a CT abdomen-pelvis was performed, which revealed a bulky right ovary, confirmed on MRI of the pelvis as an enlarged right ovary, measuring $2.9 \times 2.2 \mathrm{~cm}$ transaxially. A laparoscopic bilateral salpingo-oophorectomy was performed, and histopathological examination and immunohistochemistry confirmed the diagnosis of a Leydig cell tumor, a rare tumor accounting for $0.1 \%$ of ovarian tumors. Surgical resection led to normalization of testosterone levels.

\section{Learning points:}

- Hirsutism in postmenopausal women should trigger suspicion of androgen-secreting tumor

- Extremely elevated testosterone level plus normal DHEAS level point toward ovarian source

- Leydig cell tumor is extremely rare cause of hyperandrogenicity

\section{Background}

Leydig cell tumors (LCT) are rare ovarian tumors that belong to the group of sex cord stromal tumors, of the steroid cell tumor group. These tumors constitute $<0.1 \%$ of ovarian tumors (1). Patients with LCT typically present with signs of virilization; they usually present in postmenopausal women, but can present at any age. The mainstay of treatment is surgical removal of the tumor and the prognosis is usually favorable as most cases present at an early stage (2).

\section{Case presentation}

A 60-year-old woman of Pakistani origin who spoke no English was admitted to the hospital due to symptomatic severe spinal stenosis at the level of cervical spine (she subsequently underwent a successful anterior cervical discectomy and fusion procedure (ACDF) during the admission). She had a past history of bronchial asthma and well-controlled type 2 diabetes mellitus. During her pre-operative work-up, a nurse on the ward reported to the medical team that 'this gentleman is awaiting his 
operation', having mistaken the female patient for a male. This led the medical team to perform a more detailed review.

Upon review, the patient had signs of virilization, including prominent facial hirsutism (Ferriman-Gallwey score 18) (3), frontal balding, coarse facial features and clitoromegaly. There was no acne or deepening of the voice. Body mass index was in the obese category at $30.7 \mathrm{~kg} / \mathrm{m}^{2}$, and there were no stigmata of Cushing's syndrome. Examination of the abdomen was normal with no palpable masses or lymphadenopathy.

The patient had achieved menopause at 53 years of age, and there was no postmenopausal bleeding. Her menstrual history had been normal prior to the menopause.

\section{Investigation}

Investigations revealed that her full blood count, renal profile, liver function and thyroid function tests were normal. A sex hormone panel was performed with results as listed in Table 1. Her testosterone level was markedly elevated at $21 \mathrm{nmol} / \mathrm{L}(0.4-1.7)$, a level that correlated with the clinical findings and prompted a search for an androgen-secreting tumor. The DHEAS level was normal, and the FSH was inappropriately normal in a postmenopausal woman.

Table 1 Sex hormone and metabolic profile before and after surgery.

\begin{tabular}{|c|c|c|c|}
\hline & $\begin{array}{l}\text { Before } \\
\text { surgery }\end{array}$ & $\begin{array}{c}\text { After } \\
\text { surgery }\end{array}$ & $\begin{array}{c}\text { Reference } \\
\text { values }\end{array}$ \\
\hline \multicolumn{4}{|l|}{ Sex hormones } \\
\hline Total testosterone, nmol/L & 21 & 0.2 & $0.4-1.7$ \\
\hline DHEAS, $\mu \mathrm{mol} / \mathrm{L}$ & 2.7 & - & $0.7-7.5$ \\
\hline $\begin{array}{l}\text { Sex hormone-binding } \\
\text { globulin, nmol/L }\end{array}$ & 58 & - & $17-114$ \\
\hline FSH, IU/L & 4 & - & $1.5-21.4$ \\
\hline LH, IU/L & 6.1 & - & $3-18.7$ \\
\hline \multicolumn{4}{|l|}{ Tumor markers } \\
\hline CA19.9, IU/mL & 5.2 & - & $0-35$ \\
\hline CA125, IU/mL & 2.5 & - & $0-37$ \\
\hline \multicolumn{4}{|l|}{ Complete blood count } \\
\hline Hemoglobin level, g/dL & 12.7 & 11.1 & $12.1-15.1$ \\
\hline $\mathrm{RBC} \times 10^{12 / L}$ & 4.3 & 3.63 & $4.2-5.4$ \\
\hline $\mathrm{MCV}, \mathrm{fL}$ & 92 & 90.5 & $76-96$ \\
\hline \multicolumn{4}{|l|}{ Metabolic profile } \\
\hline Total cholesterol, mmol/L & 4.8 & 3.8 & $<5.2$ \\
\hline LDL-C, mmol/L & 2.47 & 1.56 & $<3.36$ \\
\hline $\mathrm{dHDL}, \mathrm{mmol} / \mathrm{L}$ & 1.08 & 1.33 & $>1.55$ \\
\hline Triglyceride, mmol/L & 2.64 & 2.06 & $<1.69$ \\
\hline $\mathrm{HgA} 1 \mathrm{C}, \mathrm{mmol} / \mathrm{mol}$ & 42 & 45 & $34-43$ \\
\hline
\end{tabular}

A contrast-enhanced CT abdomen was performed and revealed a bulky right ovary compared to the left, with attenuation values not in keeping with a simple cyst. Further evaluation with contrast-enhanced MRI pelvis revealed asymmetrical ovaries with a relatively enlarged right ovary, measuring $2.9 \times 2.2 \mathrm{~cm}$ transaxially. The central aspect was T2 hyper-intense and non-enhancing post gadolinium (Figs 1 and 2). No ascites, focal fluid collections or pelvic lymphadenopathy was identified.

\section{Treatment}

A diagnosis of an androgen-secreting tumor of the right ovary causing virilization was made. The patient was referred for gynecology opinion and a laparoscopic bilateral salpingo-oophorectomy was performed without complication.

Immunohistochemistry showing neoplastic cells that stained positive for inhibin and melanin A, while cytokeratin CD30 and alpha-fetoprotein staining were negative. The proliferative index was less than 5\%. These findings were confirmatory of an androgen-secreting Leydig cell tumor.

The tumor was staged according to the staging classification of International Federation of Gynaecology and Obstetrics (FIGO) (4). This tumor was classified with an early stage of $1 \mathrm{~A}$ in view of the unilateral encapsulated findings.

\section{Outcome and follow-up}

Following removal of the tumor, the patient's testosterone level had normalized. The hirsutism subsided and her baldness improved.

\section{Discussion}

Virilization in a female may manifest with hirsutism, increased muscle strength, frontal hair thinning, male pattern baldness, clitoromegaly, acne, deepening of the voice and menstrual disturbance (5). These changes are driven by elevated androgen levels including testosterone, dehydroepiandrosterone (DHEA) and dehydroepiandrosterone sulfate (DHEAS). True virilization must be distinguished in clinical practice from hypertrichosis or mild hirsutism (Ferriman-Gallwey score 8-15) (3) as the work-up for such patients will be different. Rapid onset of hirsutism, virilization, a palpable abdominal or pelvic mass or testostesrone level $>5.2 \mathrm{nmol} / \mathrm{L}$ all raise suspicion for an androgen-secreting 


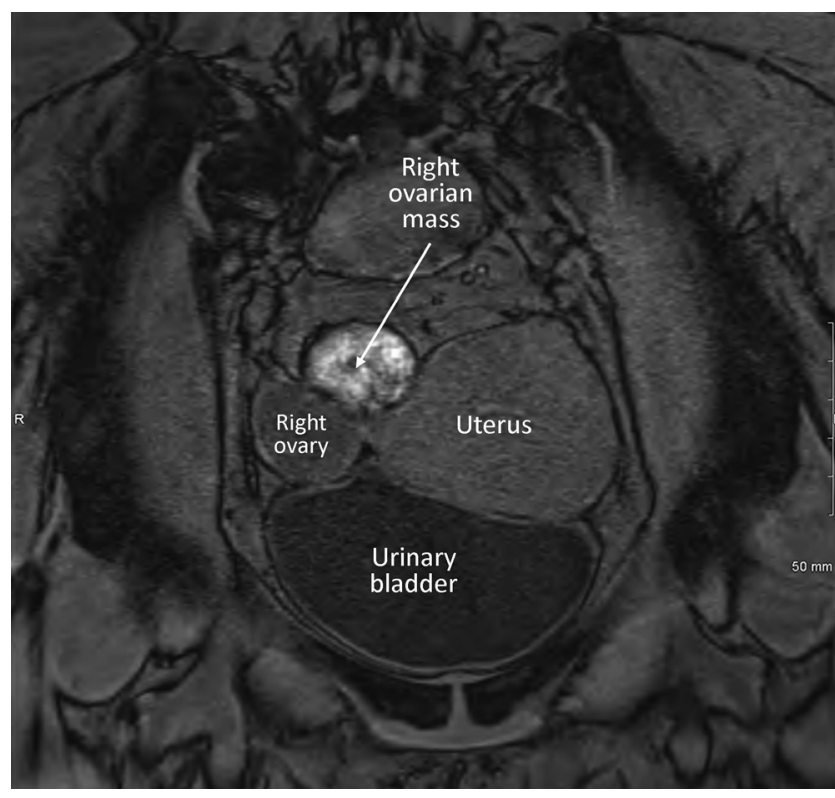

Figure 1

MRI pelvis with contrast: Coronal T1 fat saturated pre contrast.

tumor (6).Testosterone is produced in females at a rate of $0.1-0.4 \mathrm{mg} /$ day, with $25 \%$ of the circulating testosterone being secreted by the ovaries, $25 \%$ by the adrenals and $50 \%$ arising from the peripheral metabolism of prehormones (7). In contrast, DHEA is produced mainly by the adrenals (50\%), with the ovaries and conversion from circulating DHEAS accounting for $20 \%$ and $30 \%$ of circulating levels

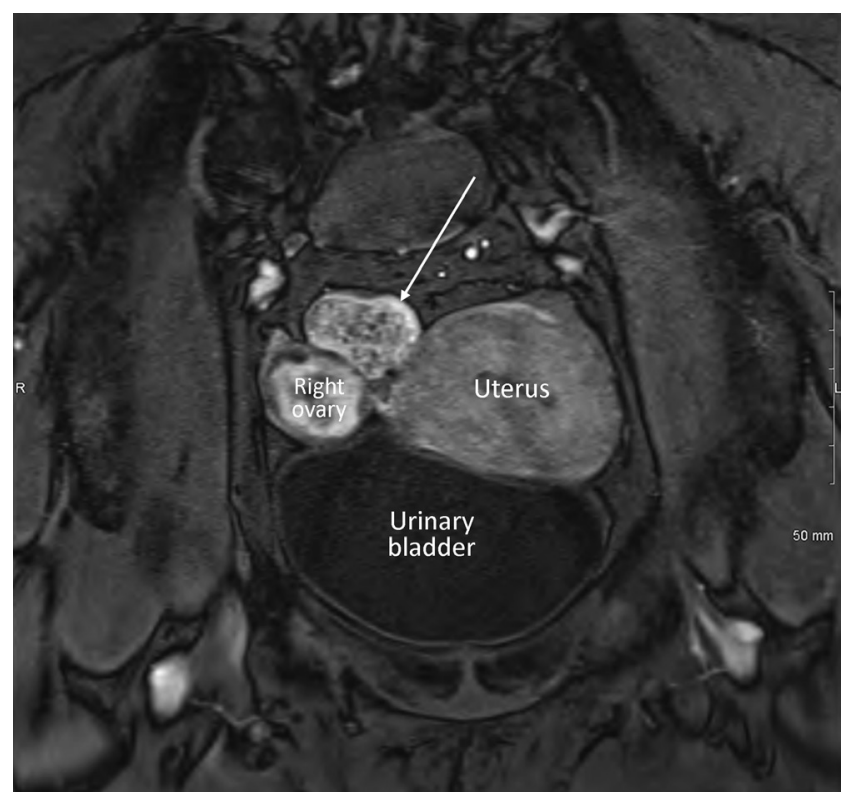

Figure 2

MRI pelvis with contrast: Coronal T1 Fat Sat post gadolinium. The arrow: peripheral enhancement that corresponds to the orange rim in the stained histological gross specimen.

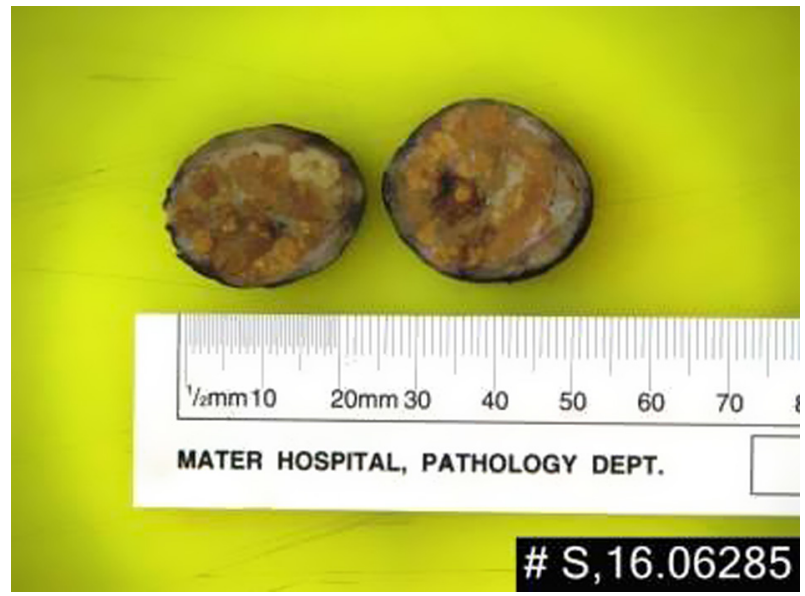

\section{Figure 3}

Gross appearance of the right ovary. Macroscopically, the right ovarian mass had a smooth surface and the ovary was enlarged, measuring $30 \times 27 \times 18 \mathrm{~mm}$ (Fig. 3). Histopathological sectioning showed an encapsulated lesion, multilobulated, orange and cream in appearance and confined within the ovary. A myxoid area was noted with no mitosis or necrosis. Features were consistent with a Leydig cell tumor (steroid cell tumor) (Fig. 4).

respectively. In view of this, proportional predilection of DHEA production from the adrenals, a markedly elevated testosterone level in a female with a normal level of DHEA is highly suggestive of an androgen-producing ovarian tumor (8); in addition, in a postmenopausal woman presenting with virilization, an androgen-producing ovarian tumor is more common than an adrenal tumor. Table 2 has listed the differential diagnosis of virilization in female with corresponding testosterone and DHEAS levels and clinical severity.

The World Health Organization has classified ovarian tumors based on their most probable tissue of origin:
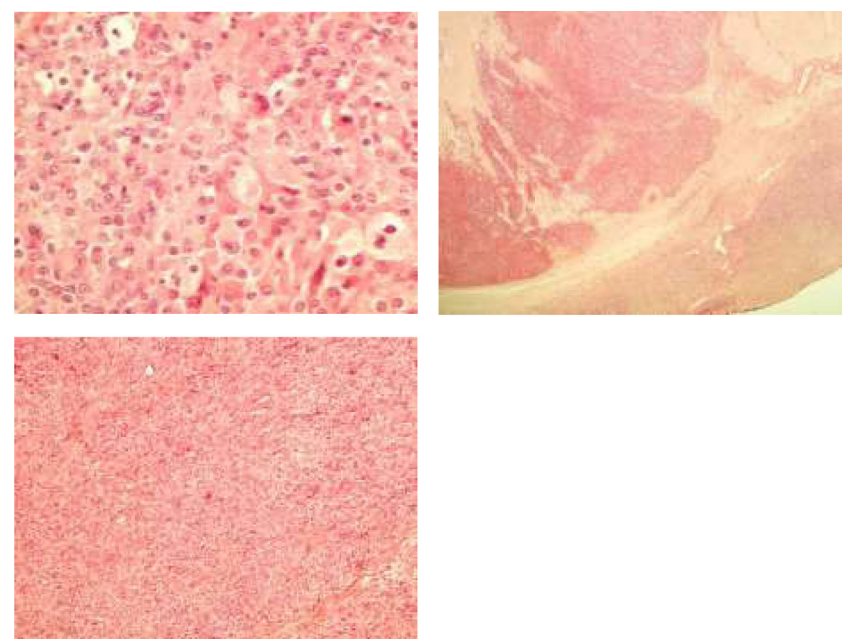

Figure 4

Histological sectioning of the ovarian mass. 
surface epithelial (65\%), germ cell (15\%), sex cord-stromal (10\%), metastases (5\%) and miscellaneous (9). Over 90\% of ovarian neoplasms arise from the epithelial surface of the ovary, with the remainder originating from germ cells or stromal cells. Stromal cell tumors are subdivided into a number of subtypes, including steroid cell tumors (9).

Steroid cell tumors account for $0.1 \%$ of all ovarian tumors and are defined as ovarian tumors mainly composed of steroid hormone-secreting cells (2). They can be further subclassified into stromal luteoma, steroids cell tumors not otherwise specified (NOS) and Leydig cell tumors (LCTs) that do not have another component as in our case (10). Steroid cell tumor NOS is the most common of the 3 subtypes accounting for almost $60 \%$ of steroid cell tumors, and LCTs therefore, as the rarest subtype of an already rare sub-division of ovarian tumor, are extremely rare (2)

The typical presentation for a LCT is with androgenic manifestations in a postmenopausal woman, as was the case in our patient. Less commonly, patients may present with estrogenic manifestations such as menorrhagia, postmenopausal bleeding and endometrial adenocarcinoma (1).

Surgical tumor resection is the main modality of treatment, and was successfully pursued in our patient, with an excellent biochemical response. LCTs generally run a benign course and neither clinical recurrence nor metastasis have been reported.

In summary, we present a case of a postmenopausal woman with an incidental diagnosis of virilization when she presented to the hospital with an unrelated problem. Further investigations confirmed significant

Table 2 Main causes of virilization in female.

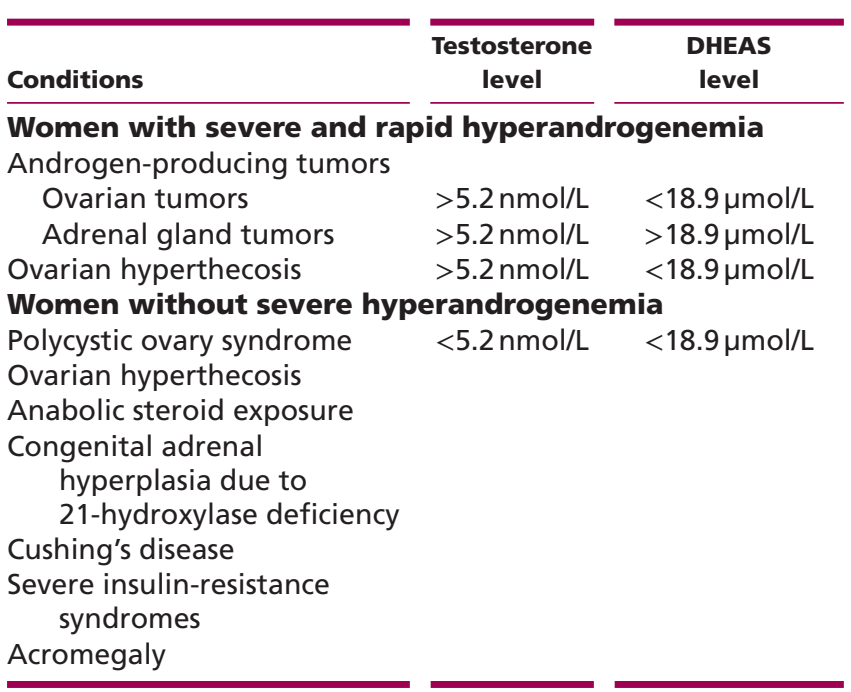

hyperandrogenaemia suggesting an ovarian tumor. Pelvic imaging revealed a bulky right ovary and surgical resection proceeded without complication, with an excellent biochemical response. Histological examination of the resected specimen confirmed the diagnosis of LCT of the right ovary. LCT of the ovary is an extremely rare type of ovarian neoplasm, which typically presents in a postmenopausal woman with androgenic manifestations. A very significantly elevated testosterone level $(>5.2 \mathrm{nmol} / \mathrm{L})$ should prompt a search for an androgensecreting tumor, while a concomitantly normal DHEA directs the diagnosis toward hyperandrogenaemia of ovarian rather than adrenal origin.

Declaration of interest

The authors declare that there is no conflict of interest that could be perceived as prejudicing the impartiality of the research reported.

\section{Funding}

This research did not receive any specific grant from any funding agency in the public, commercial or not-for-profit sector.

Patient consent

Verbal consent was taken.

Author contribution statement

Khaled Aljenaee, Sulaiman Ali, Seong Keat Cheah, Tommy Kyaw Tun, Seamus Sreenan and John $\mathrm{H}$ McDermott are caring for the patient. Neil Hickey is the radiologist responsible for reporting her scans. Owen MacEneaney and Niall Mulligan are the pathologists who reviewed her pathology. All contributed to the writing of the article, editing and reviewing the submission.

\section{References}

1 Hayes MC \& Scully RE 1987 Ovarian steroid cell tumors (not otherwise specified). A clinicopathological analysis of 63 cases. American Journal of Surgical Pathology 11 835-845. (doi:10.1097/00000478-198711000-00002)

2 Hanby AM, walker C. Tavassoli FA \& Devilee P 2004 Pathology and Genetics: Tumours of the Breast and Female Genital Organs. WHO Classification of Tumours series - volume IV. Lyon, France: IARC Press. Breast Cancer Research. 6 133. (doi:10.1186/bcr788)

3 Ferriman D \& Gallwey JD 1961 Clinical assessment of body hair growth in women. Journal of Clinical Endocrinology and Metabolism 21 1440-1447. (doi:10.1210/jcem-21-11-1440)

4 Prat J 2015 FIGO Committee on Gynecologic Oncology FC on G. FIGO's staging classification for cancer of the ovary, fallopian tube, and peritoneum: abridged republication. Journal of Gynecologic Oncology 26 87-89. (doi:10.3802/jgo.2015.26.2.87)

5 McDermott MT ed. 2013 Endocrine Secrets. 6th ed. Philadelphia: Elsevier Saunders. 
6 Martin KA, Chang RJ, Ehrmann DA, RJ, Ibanez L, Lobo RA, Rosenfield RL, Shapiro J, Montori VM \& Swiglo BA 2008 Evaluation and treatment of hirsutism in premenopausal women: an endocrine society clinical practice guideline. Journal of Clinical Endocrinology and Metabolism 93 1105-1120. (doi:10.1210/jc.2007-2437)

7 Burger HG 2002 Androgen production in women. Fertility and Sterility 77 (Supplement 4) S3-S5. (doi:10.1016/S00150282(02)02985-0)

8 Derksen J, Nagesser SK, Meinders AE, Haak HR \& van de Velde CJ 1994 Identification of virilizing adrenal tumors in hirsute women.
New England Journal of Medicine 331 968-973. (doi:10.1056/ NEJM199410133311502)

9 Shahrzad Ehdaivand MD 2016 Pathology outlines - WHO classification of ovarian neoplasms. (Available at: http://www. pathologyoutlines.com/topic/ovarytumorwhoclassif.html). Accessed on 25 January 2017.

10 Ye L, Wu X, Xu L, Huang Q, Sun L, He Y \& Yang K 2007 Ovarian steroid cell tumor, not otherwise specified: a clinicopathologic study. Zhonghua bing li xue za zhi 36 516-520. (doi:10.3760/j.issn:05295807))

Received in final form 1 July 2017

Accepted 14 July 2017 